\title{
EFFECT OF USING TWO SPLINTED MINI-IMPLANTS VERSUS TWO CONVENTIONAL IMPLANTS RETAINING MANDIBULAR OVERDENTURE ON CRESTAL BONE LOSS
}

\author{
Hebatallah Tarek Abdallah*
}

\begin{abstract}
Objective: was to compare the marginal bone loss around two splinted Mini-implants and two conventional implants retaining mandibular overdenture.

Material and methods: Fourteen completely edentulous male patients were selected from those attended the out-patient clinic of Removable Prosthodontic Department, Faculty of DentistryAin Shams University to participate in this study. Based on the cone beam computed tomographic (CBCT) assessment, the selected patients were divided into two equal groups: Group (I): Patients received conventional complete maxillary dentures opposed by mandibular overdentures supported and retained by two splinted Mini-implants of $2.5 \mathrm{~mm}$ diameter and $12 \mathrm{~mm}$ length in the interforaminal region. Group (II): Patients received conventional complete maxillary dentures opposed by mandibular overdentures supported and retained by two conventional implants of $4 \mathrm{~mm}$ diameter and $12 \mathrm{~mm}$ length placed in the lateral-canine regions. CBCT records were obtained upon Overdenture Insertion (Baseline), Six Months, Twelve Months after insertion. The Mesial, Distal, Buccal and Lingual marginal bone heights around the implants were evaluated, using the linear measurement system of the software with flat panel detector supplied by the cone beam CT.
\end{abstract}

Results: Peri-Implant Bone Loss in Group (I): Six months following denture insertion calculated means of the measured bone loss for the Mesial surfaces were $0.55 \pm 0.1 \mathrm{~mm}$, for the Distal surfaces were $0.68 \pm 0.03 \mathrm{~mm}$, for the Buccal surfaces were $0.53 \pm 0.12 \mathrm{~mm}$ and for the Lingual surfaces were $0.51 \pm 0.03 \mathrm{~mm}$. The calculated means of the measured bone loss was statistically significant at $\mathrm{P}<0.05$. At twelve months following denture insertion, the calculated means of the measured bone loss for the Mesial surfaces were $0.68 \pm 0.1 \mathrm{~mm}$, for the Distal surfaces were 0.87 $\pm 0.7 \mathrm{~mm}$, for the Buccal surfaces were $0.69 \pm 0.1 \mathrm{~mm}$ and for the lingual surface $0.67 \pm 0.03 \mathrm{~mm}$. The calculated means of the measured bone loss were statistically significant $(\mathrm{P} \leq 0.05)$.

Peri-Implant Bone Loss in Group (II): Six months following denture insertion calculated means of the measured bone loss for the Mesial surfaces were $0.51 \pm 0.10 \mathrm{~mm}$, for the Distal surfaces were $0.62 \pm 0.08 \mathrm{~mm}$, for the Buccal surfaces were $0.51 \pm 0.09 \mathrm{~mm}$ and for the Lingual surfaces were $0.50 \pm 0.09 \mathrm{~mm}$. The calculated means of the measured bone loss were statistically significant $(\mathrm{P} \leq 0.05)$.

\footnotetext{
* Lecturer of Prosthodontics, Faculty of Dentistry. Ain Shams University
} 
Twelve months following denture insertion calculated means of the measured bone loss for the Mesial surfaces were $0.64 \pm 0.10 \mathrm{~mm}$, for the Distal surfaces were $0.83 \pm 0.06 \mathrm{~mm}$, for the Buccal surfaces were $064 \pm 0.09 \mathrm{~mm}$ and for the Lingual surfaces were $0.64 \pm 0.08 \mathrm{~mm}$. The calculated means of the measured bone loss were statistically significant $(P \leq 0.05)$. The calculated means of the measured bone loss in group I of the two splinted Mini implants was higher than in group II of the two conventional implants for the Mesial, distal , buccal and lingual surfaces and over all bone loss at 6 months and 12 months but was found not statistically significant at $\mathrm{P}<0.05$.

Conclusions: Within the limitation of this study, it could be concluded that marginal bone loss around two splinted Mini implants supporting and retaining mandibular complete overdenture is higher than the marginal bone loss around two conventional implants supporting and retaining mandibular complete overdenture although the difference was statistically insignificant.

\section{INTRODUCTION}

According to the academy of prosthodontic terms, dental implant is defined as a prosthetic device of alloplastic material implanted into the oral tissues beneath mucosal and/or periosteal layer, and/ or within the bone to provide retention and support for a fixed or removable prosthesis. ${ }^{(1)}$

Oral implants have revolutionized the practice of dentistry. Many studies have focused on the mechanisms of tissue integration and the possibilities to secure long-term success. The concept of osseointegration was developed by BRANEMARK in the middle of the 1960s and led to the predictable long-term success of oral implants. ${ }^{(2)}$

Implant diameter is measured from the widest thread to the same point on the opposite side of the implant. From a biomechanical standpoint, the use of wider implants allows engagement of a maximal amount of bone and improved distribution of stress in the surrounding bone. ${ }^{(3)}$

The use of wide implants, however, is limited by the width of the residual ridge and esthetic requirements for a natural emergence profile. ${ }^{(3)}$

The advantages of using wide-diameter implants include providing more bone-to-implant contact (4), bicortical engagement, immediate placement in failure sites, and a reduction in abutment stresses and strain. ${ }^{(5)}$ Implants also have a more favorable distribution of masticatory forces, increasing the surface reduces stress on any point of the interface on occlusal loading. ${ }^{(6)}$

Opposition to wider implants has focused mostly on possible over-instrumentation and heat generation. ${ }^{(4)}$ The use of implants less than 5.0 $\mathrm{mm}$ in diameter has been proposed to reduce heat generated in the drilling process and subsequent bone damage. (7)

Narrow-diameter implants were used for residual ridges that were too narrow and for edentulous spaces with limited interdental width. Narrow diameter implants include small diameter implants ranging from $2.4 \mathrm{~mm}$ to $3 \mathrm{~mm}$ and Mini dental implant ranging from $1.8 \mathrm{~mm}$ to $2.4 \mathrm{~mm}$. ${ }^{(8)}$

Narrow-diameter implants have been used to support conventional denture with atrophied mandible when the implant site is less than $5 \mathrm{~mm}$ in diameter and bone grafting is not possible. ${ }^{(9)}$

These so-called Mini implants were formerly introduced to support fixed provisional restorations ${ }^{(10)}$. Recently successful oral rehabilitation with Mini implants in more definitive treatments has been reported for partially and completely edentulous patients ${ }^{(11,12,13)}$.

Mini dental implants, also known as MDI's, consist of a titanium dental implant that acts as a tooth root replacement and a retainer fixture. The Mini implants concept was developed over 20 years ago by Manhattan dentist, Vector I, Sendax. 
He created the unique design of the dental product as a transitional device to help support fixed bridge replacements for missing teeth. He suggested that Mini implants could function free standing or in combination with natural tooth supports and/or larger conventional type implants. ${ }^{(10)}$

The demand for Mini-implants in dental practice is to be immediate or long-term stabilizer to the removable prosthesis for the edentulous jaw. Miniimplants are a highly successful implant option. The use of Mini-implants has shown a significant increase in interest as a result of the vast amount of literature reporting high success rates ${ }^{(14)}$.

The implants are relatively affordable and overall patient satisfaction is excellent. Miniimplants have become a common treatment option for improving retention of lower dentures. ${ }^{(15)}$

Splinted Mini-implants supporting a mandibular overdenture showed less marginal bone loss than non-splinted Mini-implants. When the Miniimplants were splinted together with a rigid superstructure, it presented better behavior and the stresses that developed were lower. ${ }^{(16)}$.

\section{MATERIAL AND METHODS}

\section{Patient Selection:}

Fourteen completely edentulous male patients were selected from those attending the out-patient clinic of Removable Prosthodontic Department, Faculty of Dentistry-Ain Shams University to participate in the study.

\section{Inclusion Criteria for Patient Selection:}

- Male patient's age ranged from 55 to 65 years with mean age of 60 years old.

- Patients had completely edentulous maxillary and mandibular arches.
- Only patients with good oral hygiene were enrolled in the study.

- Patients with Angle Class-I maxillo-mandibular relationship and sufficient inter-arch spaces were selected.

- Residual alveolar ridges were covered with firm healthy mucosa, free from any signs of inflammation, ulceration or flabbiness.

\section{Exclusion Criteria:}

- Patients with systemic diseases that might affect bone quality, contribute to bone resorption, increase surgical risk, delay or complicate postoperative healing.

- Patients with any muscular or TMJ disorders and patients with parafunctional habits

- Patients with severe cardiovascular diseases, metabolic disorders, history of previous radiotherapy and chemotherapy, osteoporosis, allergies and impaired psychological conditions.

- Smoking patients.

Primary impressions were made using irreversible hydrocolloid impression material* in properly selected and modified stock trays and poured in dental stone to obtain study casts. Occlusion blocks were constructed on the study casts, diagnostic wax wafer jaw relation records were made at proper vertical and horizontal relations, then the casts were mounted on a fixed condylar path articulator.

Trial set-up of artificial teeth was carried out on the mounted diagnostic casts to evaluate the ridge relationship, the available inter-arch space. Diagnostic Panoramic radiographs were made for all patients to evaluate the presence or absence of remaining roots, impactions or any other pathological lesions that might complicate placement of dental implants inter-foraminally, locate the position of

\footnotetext{
*Cavex Holland B.V., P.O. Box 852-2006 R W Haarlem, Holland.
} 
mental foramina, level of inferior alveolar canal and detection of anterior looping of mental nerve.

Patients received complete denture constructed by conventional technique and follow up was done for two weeks before surgery.

\section{Patient Grouping:}

Based on the final cone beam computed tomographic (CBCT) assessment patients were divided into two equal groups:

Group (I): Patients received conventional complete maxillary dentures opposed by mandibular overdentures supported and retained by two splinted Mini-implants of $2.5 \mathrm{~mm}$ diameter and $12 \mathrm{~mm}$ length $* *$ in the interforaminal region

Group (II): Patients received conventional complete maxillary dentures opposed by mandibular overdentures supported and retained by two conventional implants of $4 \mathrm{~mm}$ diameter and $12 \mathrm{~mm}$ length** placed in the lateral-canine regions.

Bilateral nerve block and field block anaesthesia were given using Ubistesin Forte $4 \%$ anaesthetic solution. After the anaesthetic effect was confirmed the surgical stent was properly seated in position in the patient's mouth and a dental probe was inserted into the notches made in the stent to puncture the mucosa covering the alveolar ridge.

For group I patients: These punctures represented the sites of implant insertion which appeared as bleeding points. Cortical drill was used to penetrate cortical bone.A pilot drill $1.1 \mathrm{~mm}$ in diameter was used to drill bone up and down in a vertical direction. Light intermittent finger pressure was applied and irrigation at 800 RPM speed until the desired length was reached. The implant was picked up from the sterile vial and directly inserted into the prepared site. The implant was manually threaded until resistance was felt. It was then threaded into final position with ratchet wrench until the mark on the neck portion was no more visible, The square head of implants trimmed to the first mark that allow fixed abutment heights suitable for the available inter arch space for all patients groups. (fig.1)

\section{Bar attachment construction:}

Closed tray impression was made with rubber base putty impression material using plastic transfer coping and implant analogue. (fig.2)Stone was poured to get cast with implant analogue in its place representing patient's mouth.

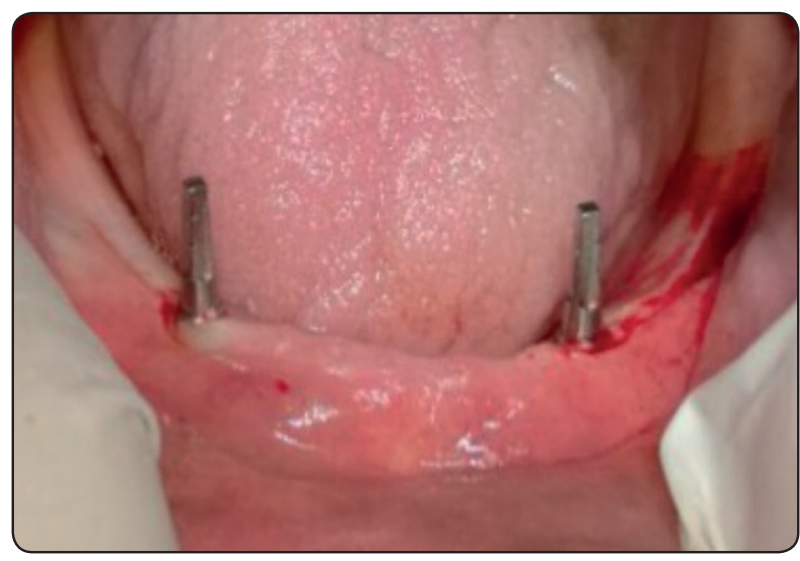

Fig. (1): Mini implant with square head

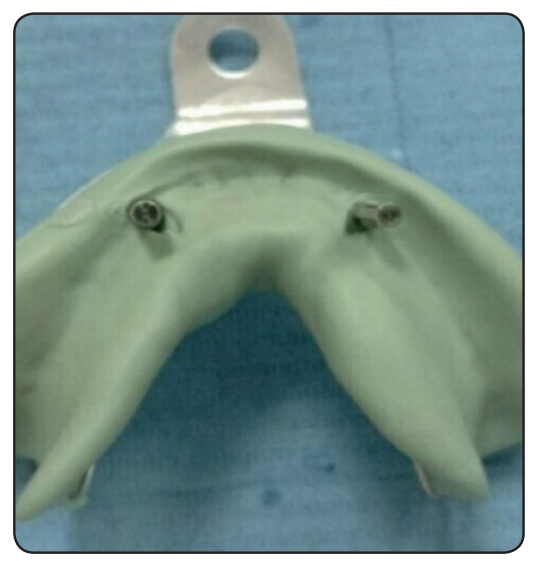

Fig. (2): Closed tray impression with transfer coping and implant analogue in place.

**INNO Cowellmedi Co., Ltd. 48, Hakgam-daero 221 beon-gil, Sasang-gu, Busan, 617-801, Republic of Korea 
For group II patients: The flap area was identified. Using bard-parker blade No. 15, two mid crestal incisions in the lateral-canine areas extending $2 \mathrm{~mm}$ mesially and distally without crossing the midline were made at the proposed implant sites with relaxing incision extending labially from the crest of the ridge to the depth of the vestibule. A full thickness mucoperiosteal flap was reflected using a sharp mucoperiosteal elevator. The lingual mucoperiosteum was also slightly dissected. The surgical stent was seated in the patient's mouth and under copious saline irrigation, drilling started with light intermittent finger pressure and at speed of $1000 \mathrm{rpm}$ and $30 \mathrm{~N} /$ $\mathrm{cm}$ torque. The implants were threaded into the bone in a clockwise direction under saline irrigation until its top flushed with the bone surface using the torque wrench. The abutments were then screwed into position to the fixtures. The mucoperiosteal flaps were repositioned and sutured with 3-0 black silk interrupted sutures and patients were recalled seven days after surgery to remove the sutures.

One week after implants insertion the following adjustments were carried out:

For group I patients: Metal custom made bar constructed splinting the two mini implants was ready and after try in was done bar was cemented

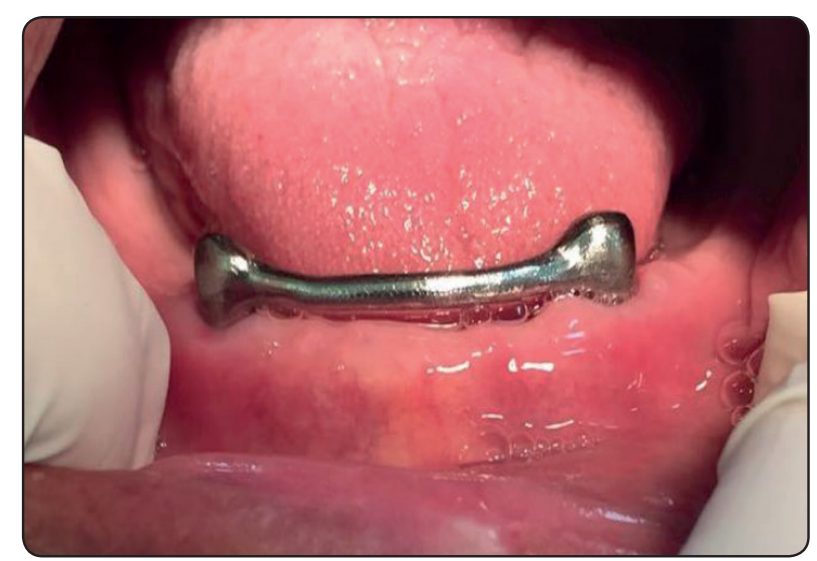

Fig. (3) The two splinted Mini implants

*Oranwash ${ }^{\circledR}$ L, Zhermack, Italy

**Dura-Liner II, Reliance Dental Mfg. Co. Worth, IL, USA with self adhesive resin cement "G-Cem capsule" and excess removed around the bar and mucosa. A fast-setting chair side Poly-vinyl siloxane material (PVS) * was loaded onto the fitting surface of the lower denture, then it was seated in the patient's mouth to locate the position of the bar, after few minutes the denture was removed from the patient's mouth and area marked by the bar removed using large round bur. The denture was inserted in the patient's mouth to ensure that it was passively seated. Small amount of putty PVS used to block under and around the bar for pick up procedure.Clip seated in it's place and Auto-polymerizing acrylic resin ** in dough stage was applied in the space created in the denture opposite to the bar clip, and the overdenture was seated on the model. Firm steady pressure was applied on the overdenture bilaterally till complete curing of the resin. The excess material was trimmed and smoothened,

For group II patients: Auto-polymerizing acrylic resin was applied into the depressions of the mandibular denture corresponding to the ball abutments sites and the denture was fully seated in the patient's mouth. With the maxillary denture in place the patient was guided to close in centric occluding relation till complete curing occurred.(Fig. 3-6)

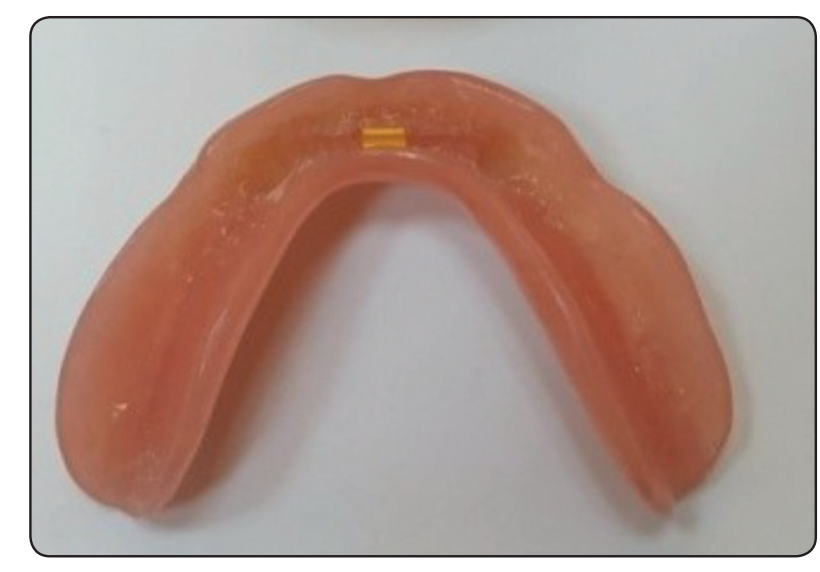

Fig. (4) clip for splinted Mini implants 


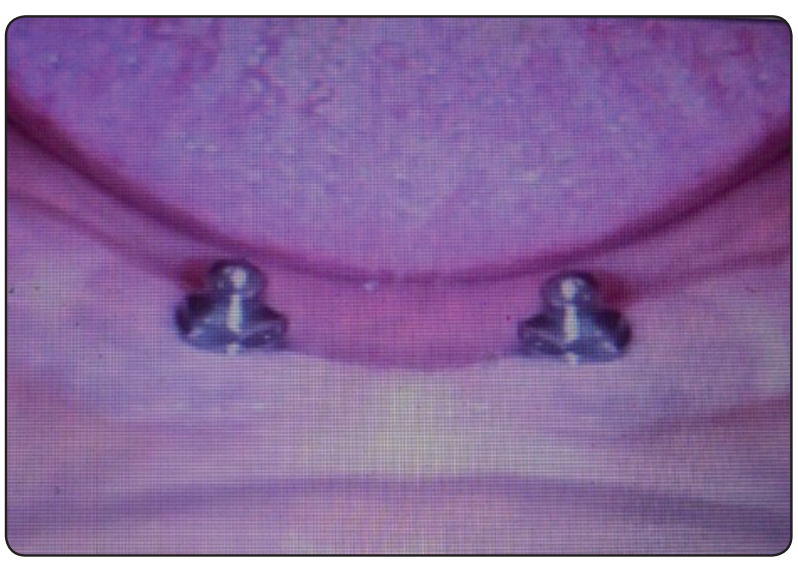

Fig. (5) Two conventional implants

All patients were scheduled for follow up visits to evaluate marginal bone height changes at the Mesial (M), Distal (D), Buccal (B), and lingual (L) surfaces of each implant using cone beam computed tomography $(\mathrm{CBCT})^{*}$.

CBCT records were obtained upon Overdenture Insertion (Baseline), Six Months and Twelve Months after insertion. The Mesial, Distal, Buccal and Lingual marginal bone heights around the implants were evaluated, using the linear measurement system of the software** with flat panel detector supplied by the cone beam CT.

The reconstructed 3D images were saved as Digital Imaging and Communications in Medicine (DICOM) files. The three dimensional position of each implant in the alveolar bone was detected by the software. Images were analyzed on the MultiPlanar Reformat screen (MPR) and all measures were done by single experienced radiologist.

Numerical data were explored for normality by checking the data distribution, calculating the mean and median values, evaluating histograms and normality curves and using Kolmogorov-Smirnov and

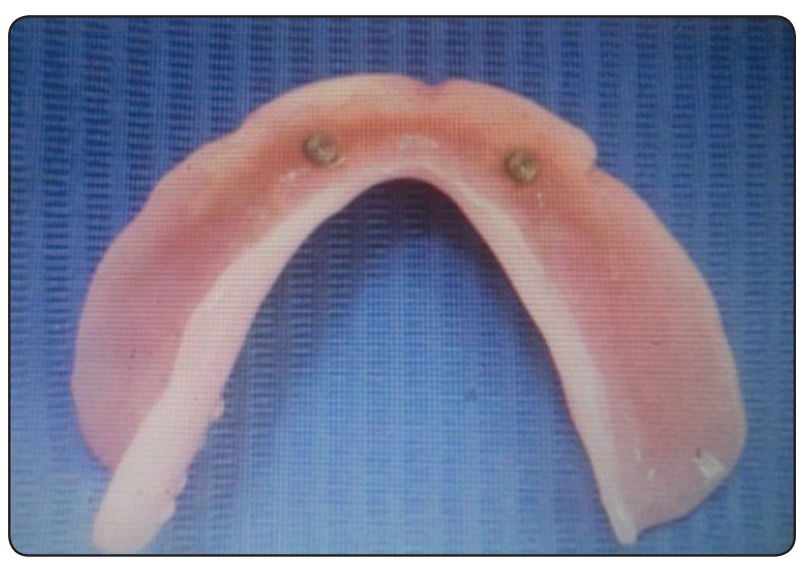

Fig. (6) Metal housing for conventional implants

Shapiro-Wilk tests.

Data were presented by mean, standard deviation (SD). Independent t-test was used for comparison between groups. ANOVA for repeated measures was used for comparison between follow up periods followed by simple main effect. The significance level was set at $\mathrm{P} \leq 0.05$.

Statistical analysis was performed with IBM SPSS*Statistics Version 20 for Windows.

\section{RESULTS}

\section{Peri-Implant Bone Loss by Time Within Each Group.}

$\operatorname{Group}(I)$ :

\section{Six Months Following Denture Insertion:}

The calculated means of the measured bone loss for the Mesial surfaces were $0.55 \pm 0.1 \mathrm{~mm}$, for the Distal surfaces were $0.68 \pm 0.03 \mathrm{~mm}$, for the Buccal surfaces were $0.53 \pm 0.12 \mathrm{~mm}$ and for the Lingual surfaces were $0.51 \pm 0.03 \mathrm{~mm}$. The calculated means of the measured bone loss were statistically significant $(\mathrm{P} \leq 0.05)$.

\footnotetext{
* i-CAT Next Generation; Imaging Sciences International LLC.1910 North Penn Road Hatfield, PA.19440. USA.

** i-CATVision; iQDesk-version1.9.3.13; Imaging Sciences International LLC.1910 North Penn Road Hatfield, PA.19440. USA.
} 


\section{Twelve Months Following Denture Insertion:}

The calculated means of the measured bone loss for the Mesial surfaces were $0.68 \pm 0.1 \mathrm{~mm}$, for the Distal surfaces were $0.87 \pm 0.7 \mathrm{~mm}$, for the Buccal surfaces were $0.69 \pm 0.1 \mathrm{~mm}$. for the lingual surface $0.67 \pm 0.03 \mathrm{~mm}$. The calculated means of the measured bone loss were statistically significant $(\mathrm{P} \leq 0.05)$.

TABLE (1) The difference in marginal bone loss within the two splinted Mini implants group.

\begin{tabular}{|c|c|c|c|c|c|}
\hline \multirow{2}{*}{} & \multicolumn{2}{|c|}{$0-6$ months } & \multicolumn{2}{c|}{$0-12$ months } & \multirow{2}{*}{ P value } \\
\cline { 2 - 5 } & Mean & Std. & Mean & Std. & \\
\hline Mesial & 0.55 & 0.1 & 0.68 & 0.1 & $<0.001^{*}$ \\
\hline Distal & 0.68 & 0.03 & 0.87 & 0.7 & $<0.001^{*}$ \\
\hline Buccal & 0.53 & 0.12 & 0.69 & 0.1 & $<0.001^{*}$ \\
\hline Lingual & 0.51 & 0.03 & 0.67 & 0.03 & $<0.001^{*}$ \\
\hline
\end{tabular}

**SPSS Inc., IBM Corporation, NY, USA

\section{Group (II):}

\section{Six Months Following Denture Insertion:}

The calculated means of the measured bone loss for the Mesial surfaces were $0.51 \pm 0.10 \mathrm{~mm}$,

for the Distal surfaces were $0.62 \pm 0.08 \mathrm{~mm}$, for the Buccal surfaces were $0.51 \pm 0.09 \mathrm{~mm}$ and for the Lingual surfaces were $0.50 \pm 0.09 \mathrm{~mm}$. The calculated means of the measured bone loss were statistically significant $(\mathrm{P} \leq 0.05)$.

\section{Twelve Months Following Denture Insertion:}

The calculated means of the measured bone loss for the Mesial surfaces were $0.64 \pm 0.10 \mathrm{~mm}$,

for the Distal surfaces were $0.83 \pm 0.06 \mathrm{~mm}$, for the Buccal surfaces were $064 \pm 0.09 \mathrm{~mm}$ and for the Lingual surfaces were $0.64 \pm 0.08 \mathrm{~mm}$. The calculated means of the measured bone loss were statistically significant $(\mathrm{P} \leq 0.05)$.
TABLE (2) The difference in marginal bone loss within the two conventional implants group

\begin{tabular}{|c|c|c|c|c|c|}
\hline \multirow{2}{*}{} & \multicolumn{2}{|c|}{$0-6$ months } & \multicolumn{2}{c|}{$0-12$ months } & \multirow{2}{*}{ P value } \\
\cline { 2 - 5 } & Mean & Std. & Mean & Std. & \\
\hline Mesial & 0.51 & 0.10 & 0.64 & 0.10 & $<0.001^{*}$ \\
\hline Distal & 0.62 & 0.08 & 0.83 & 0.06 & $<0.001^{*}$ \\
\hline Buccal & 0.51 & 0.09 & 0.64 & 0.09 & $<0.001^{*}$ \\
\hline Lingual & 0.50 & 0.09 & 0.64 & 0.08 & $<0.001^{*}$ \\
\hline
\end{tabular}

\section{Comparison Between the Amounts of Bone loss in Both Groups.}

The calculated means of the measured bone loss in the group I of two splinted Mini implants were higher than group II of two conventional implants for the Mesial, distal , buccal and lingual surfaces and over all bone loss at 6 months and the difference was statistically insignificant ( $\mathrm{P} \leq 0.05$ ).

TABLE (3) The difference in bone height loss in Mini implants group versus conventional implants group during the follow up intervals (0-6months)

\begin{tabular}{|c|c|c|c|c|c|}
\hline \multirow{2}{*}{$\begin{array}{c}\text { 0- } 6 \\
\text { months }\end{array}$} & \multicolumn{2}{|c|}{ Mini implant } & \multicolumn{2}{|c|}{$\begin{array}{c}\text { Conventional } \\
\text { implants }\end{array}$} & \multirow{2}{*}{ P value } \\
\cline { 2 - 5 } & Mean & Std. & Mean & Std. & \\
\hline Mesial & 0.55 & 0.1 & 0.51 & 0.10 & 0.4687 \\
\hline Distal & 0.68 & 0.03 & 0.62 & 0.08 & 0.0879 \\
\hline Buccal & 0.53 & 0.12 & 0.51 & 0.09 & 0.7304 \\
\hline Lingual & 0.51 & 0.03 & 0.50 & 0.09 & 0.7851 \\
\hline
\end{tabular}

The calculated means of the measured bone loss in the group I of two splinted Mini implants were higher than group II of two conventional implants for the Mesial, distal , buccal and lingual surfaces and over all bone loss at 12 months and the difference was not statistically significant at $\mathrm{P}<0.05$. 
TABLE (4) The difference in bone height loss in Mini implants group versus conventional implants group during the follow up intervals $(0-12$ months $)$

\begin{tabular}{|c|c|c|c|c|c|}
\hline \multirow{2}{*}{$\begin{array}{c}\text { 0- 12 } \\
\text { months }\end{array}$} & \multicolumn{2}{|c|}{ Mini implant } & \multicolumn{2}{c|}{$\begin{array}{c}\text { Conventional } \\
\text { implants }\end{array}$} & \multirow{2}{*}{ P value } \\
\cline { 2 - 5 } & Mean & Std. & Mean & Std. & \\
\hline Mesial & 0.68 & 0.1 & 0.64 & 0.10 & 0.4687 \\
\hline Distal & 0.87 & 0.7 & 0.83 & 0.06 & 0.8828 \\
\hline Buccal & 0.69 & 0.1 & 0.64 & 0.09 & 0.3449 \\
\hline Lingual & 0.67 & 0.03 & 0.64 & 0.08 & 0.3712 \\
\hline
\end{tabular}

\section{DISCUSSION}

\section{Discussion of Methodology}

This study evaluated the marginal bone loss between two splinted Mini implants and two conventional implants in patients rehabilitated with implant supported and retained mandibular complete overdentures.

Patients were precisely selected and thoroughly examined in attempt to reduce human variables and eliminate any factor or habit that might adversely affect the results of this study. This was done using comprehensive medical history, clinical examination and laboratory investigations. ${ }^{(17)}$

The age of the selected patients ranged between 55 and 65 years to avoid the effect of age changes on the condition of the oral mucosa, residual ridge, muscle tone and temporomandibular joint. ${ }^{(18)}$ Only male patients were selected to participate in this study to avoid the effect of sex related variations and to avoid the effect of sex related hormonal changes which were reported to contribute to mucosal changes and osteoporosis. ${ }^{(19)}$ Female patients were excluded due to high prevalence of post-menopausal osteoporosis, which might result in altered bone metabolism and reduced healing capacity. ${ }^{(20)}$
Diabetic patients with uncontrolled glucose levels were also excluded, as hyperglycemia was found to cause impaired wound healing and alterations in bone metabolism. ${ }^{(21)}$

Head and neck radiation therapy was another exclusion criterion, as the failure rates of implants were reported to be higher when they were placed in irradiated bone. This was attributed to the reduced resistance to infection, delayed wound healing and the potential for osteoradionecrosis after radiation treatment. ${ }^{(22)}$

Patients with bleeding disorders, cardiovascular impairment, advanced liver or valvular heart diseases present a high risk during any surgical procedure, were therefore eliminated from this study. ${ }^{(23,24)}$

All patients in this study exhibited normal Angle's class I ridge relationship to avoid subjecting the implants to abnormal forces. ${ }^{(25)}$

Smoking as a significant risk factor for failure of implant therapy ${ }^{(26)}$; as it affects the condition of oral mucosa and retards the process of osseointegration, therefore smokers were excluded from the study. ${ }^{(27)}$

Patients with history of abnormal or para-functional habits were excluded to avoid excessive load on the implants. ${ }^{(28)}$

It has been reported that one of the main causes of osseointegration failure is lack of proper oral hygiene. Therefore, Patients with poor oral hygiene were excluded to avoid the risk of peri-implant mucositis and peri-implantitis. ${ }^{(29)}$

Standard clinical and laboratory techniques were followed for the construction of the dentures for all patients. Also, same materials were used as feasible as an attempt to eliminate any factor that might affect the results of this study. An important consideration in fabricating a mandibular overdenture is to ensure sufficient space for prosthetic components of the implant attachment system. ${ }^{(30)}$ Therefore, mounted diagnostic casts and trial set-up of artificial teeth were employed for assessment of arch relationship. 
Diagnostic panoramic radiographs were made for all patients to evaluate the presence or absence of remaining roots, impactions or any other pathological lesions that might complicate placement of dental implants interforaminally, locate the position of mental foramina, level of inferior alveolar canal and detection of anterior looping of mental nerve. ${ }^{(31)}$

The prognosis of any implant-driven prosthetics depends primarily on successful osseointegration of the implants ${ }^{(32)}$. Accordingly, strict measures were followed along the course of this study to avoid potential factors that might increase the risk of implant failure.

The anterior mandibular region was selected for implant insertion where the greatest available height of bone is located between the mental foramina or anterior loops of the mandibular canal when present. In addition, this region usually presents the optimal density of bone for implant support. ${ }^{(33)}$

Preoperative and postoperative medications were given to all patients to control the risk of implant failure, postoperative infection, edema and to decrease patient apprehension. Broad spectrum antibiotics and anti-inflammatory drugs were administered to all patients. ${ }^{(34,35)}$

Broad spectrum antibiotics were administered as they were found to have a significant effect in preventing postoperative infections after implant placement and on implant survival rates. ${ }^{(36)}$

Proper control of heat generation was carefully considered for preservation of the surrounding bone cells and prevention of bone necrosis. Thus, a series of sharp drills, together with copious irrigation and intermittent pressure were carried out for osteotomy site preparation. ${ }^{(37)}$

Intermittent drilling was performed as it allows the saline solution to reach the entire length of the bony walls. In addition, it allows for the escape of bone debris and prevents clogging of the cutting edge of the drills which would decrease their cutting efficiency eventually increasing heat generation. ${ }^{(37)}$
Stresses are most evenly distributed when occlusal forces are directed at the center of the implant through its the long axis. ${ }^{(38,39)}$ Therefore, it was important to avoid inclinations both in the labiolingual and mesiodistal directions, which was accomplished by the frequent insertion of paralleling tools during drilling. This was also done to avoid challenges that might be encountered during the prosthetic stage, such as difficulty in achieving a path of insertion and premature wear of attachment components. ${ }^{(40)}$ The immediate implant loading protocol was followed in this study as the results of several studies revealed no significant difference between immediate and delayed implant loading by mandibular over dentures. ${ }^{(41-44)}$

The direct pick-up technique was used as this technique is simple, less expensive, requires less prosthetic elements and allows the patient to keep the prosthesis. Furthermore, direct pick-up technique eliminates inaccuracies associated with transfer impression and laboratory processing, resulting in an overdenture requiring less maintenance, less replacement of worn attachment parts and after care. ${ }^{(45)}$

\section{Discussion of results}

The success of implant supported and retained overdenture for long periods of time has been well established in the literature. ${ }^{(46,47)}$

All implants used in the current study for both groups revealed successful osseointegration throughout the follow up period as manifested by (1) absence of subjective complaints such as pain, dysesthesia, or paraesthesia at the implant sites, (2) absence of recurring peri-implant infection and/ or suppuration, (3) absence of perceptible implant mobility and (4) absence of radiolucencies at the implant-bone interface.

The above mentioned findings are fully consistent with implant success criteria proposed by Buser et al. ${ }^{(48)}$, Smith \& Zarb ${ }^{(49)}$, Albrektsson and Zarb et al. ${ }^{(50)}$ 
The significant decrease of marginal bone height surrounding the Mini implants in all aspects (buccal, lingual, mesial and distal) was found throughout all time intervals during this study. This bone reduction might be due to surgical trauma, bone osteotomy and healing process. This also could be attributed to the micro-damage accumulation occurring in bone after implant placement. ${ }^{51,52)}$

Further reduction of the bone height till the end of the study period might be due to mechanical factors acting on the implants: loading and forces of mastication. ${ }^{(53)}$

It has been observed that the maximum calculated mean of marginal bone loss for both groups was evident at the six-month interval and progressed slowly after. According to Cochran et al. ${ }^{(54)}$, periimplant bone remodeling after implant placement is more accentuated in the first 6 months after surgery. Other investigators such as Lee et al. ${ }^{(55)}$, and Hartman et al, ${ }^{(56)}$, consider most bone loss to occur in the first 6 months, followed by gradual stabilization till the end of follow up period. Crestal bone loss could be explained by the finding that forces applied on implants are distributed on the crestal bone rather than along the entire implant/bone interface. ${ }^{(57,58)}$

As for comparing the result of bone loss in both groups The calculated means of the measured bone loss in the group I of two splinted Mini implants was higher than group II of two conventional implants for the Mesial, distal, buccal and lingual surfaces and over all bone loss at 6 months and 12 months and was found not statistically significant at $\mathrm{P}<0.05$

Conventional implants varying diameter from 3 to $7 \mathrm{~mm}$. Increasing the diameter in a $3 \mathrm{~mm}$ implant by $1 \mathrm{~mm}$ increases the surface area by $35 \%$ over the same length in overall surface. More contact area provides increased initial stability and resistance to stresses. It has also been shown that the crestal bone surrounding the implant is the most susceptible to occlusal loading. ${ }^{(59)}$
Marginal bone loss around conventional implants supporting mandibular overdentures has been reported to range from 0.2 to $1.9 \mathrm{~mm}$ after the first year. ${ }^{(60,61)}$

Considering the effect of implant diameter, using Mini implants resulted in the highest stresses and strains both in axial and off-axial loading, when compared with standard wide implants. This might be attributed to the smaller surface area and volume of Mini implants, which places more force per square millimeter against the encasing bone than largerdiameter implants. ${ }^{(62)}$ This is because for every 0.5 $\mathrm{mm}$ increase in width, there is an increased surface area between $10 \%$ and $15 \%$ for a narrow range of diameters, and the percentage change is greater for smaller diameters and lesser for larger diameters. ${ }^{(63)}$

Souza et al. carried out a randomized control study. The number of the participants were 120 , and they were divided into three groups, compared mandibular overdentures retained by 2 or 4 mini implants with standard implants. The follow up study was 1 year. Complications such as lost implant were assessed after 3, 6, and 12 months from implant placement. The survival rate of Mini implants is not as high as that of standard implants. However, patient satisfaction evaluated by the Oral Health Impact Profile in edentulous adults after 12 months, the result indicating that the 2 or 4 Mini implants in the mandibular arch resulted in slightly better oral health-related quality of life. The mean values for most patient satisfaction and masticatory ability in Mini implants compared with standard implants items were also higher with 4 Mini implants and regarding ease in speaking, comfort, and esthetics; all groups were doing a similar effect .Souza et al. reported that implant survival rate was $89 \%, 82 \%$, and 99\% for 4 Mini implants group, 2 Mini implants, or 2 standard implants group, respectively. ${ }^{(64)}$

Beyari compared Mini dental implants, ball type single piece implant, and screw-type tapered rootform implants for supporting complete overdenture. Fourteen completely edentulous patients divided 
into two groups to evaluate the bone density and bone height changes around the implants at 0,6 , and 12 months after loading. The result proved that there was no significant difference found between the two types of implants. ${ }^{(65)}$

The attachment system should reduce denture movement without increasing the stresses on the implants. The ball and bar attachments efficiency is well addressed. Ball attachments are un-splinted, prefabricated units, they show hygienic advantages and are easily replaced, while bars show improved stability. ${ }^{(66)}$

Splinted Mini-implants with a bar decrease the bone stress level in comparison with single Miniimplants. The effects of bone stress magnitude may explain the clinical outcome, in which splinted Mini-implants supporting a mandibular over denture showed less marginal bone loss compared with nonsplinted Mini-implants. Vertical bone resorption morphology was significantly more prevalent in the latter group. ${ }^{(67)}$

\section{CONCLUSION}

Within the limitation of this study, it could be concluded that marginal bone loss around two splinted Mini implants supporting and retaining mandibular complete overdenture is higher than the marginal bone loss around two conventional implants supporting and retaining mandibular complete overdenture although the difference was statistically insignificant.

\section{REFERENCES}

1. Glossary of prosthodontics terms J Prosth dent, 2017, 117:29.

2. Branemark P-I, Breine U, Adell R, Hansson BO, Lindstrom $\mathrm{J} \&$ Ohlsson A Intra-osseous anchorage of dental prostheses. Scand J PlastReconstr Surg 1969;3: 81-100

3. Ivanoff CJ, Sennerby L, Johansson C, Rangert B, Lekholm $\mathrm{U}$. Influence of implant diameters on the integration of screw implants. An experimental study in rabbits. Int J Oral Maxillofac Surg. 1997;26:141-8.
4. Langer B, Langer L, Herrmann I \& Jorneus L: The wide fixture: a solution for special bone situations and a rescue for the compromised implant. Part 1. Int J Oral Maxillofac Implants. 1993; 8:400-8.

5. Mahon JM, Norling BK \& Phoenix RD: Effect of varying fixture width on stress and strain distribution associated with an implant stack system. Implant Dent. 2000; 9:310-20

6. Hallman M: A prospective study of treatment of severely resorbed maxillae with narrow nonsubmerged implants: results after 1 year of loading. Int $\mathrm{J}$ Oral Maxillofac Implants. 2001;16:731-6.

7. English C, Bahat O, Langer B \& Sheets CG. What are the clinical limitations of wide-diameter (4 $\mathrm{mm}$ or greater) root form endosseous implants Int J Oral Maxillofac Implants. 2000; 15:293-6.

8. Kanie T, Nagata M, Ban S. Comparison of the mechanical properties of 2 prosthetic mini-implants. Implant Dent. 2004; 13:251-6.

9. Minsk L. Interim implants for immediate loading of temporary restorations. Compend Contin Educ Dent. 2001; 22:186-94.

10. Sendax VI. Mini-implants as adjuncts for transitional prostheses. Dent Implantol Update. 1996; 7:12-15.

11. Gruber H, Solar P \& UIm C: Maxillomandibular anatomy and patterns of resorption during atrophy. Watzek G, editor: Endosseous implants: scientific and clinical aspects. Chicago, Quintessence, 1996.

12. Tallgren A: Positional changes of complete denture. A 7 years longitudi nal study. J.Prosthet Dent. 1972; 27:120-132.

13. Mac Entee MI: The prevalence of edentulism and disease related to denture. J Oral Rehabil. 1985; 12:125-207.

14. Trevor McClain G., Chad P \& Patrick C: Mini-Dental Implants: An adjunct for retention, stability, and comfort for the edentulous patient. J Oral Surg Oral Med Oral Pathol Oral Radiol Endod. 2005; 100:81-84.

15. Feine JS \& Carlsson GE; Implant overdentures: The standard of care for edentulous patients. Carol- stream, IL; Quintessence publishing: 2003.

16. Sennerby L \& Meredith N. Implant stability measurements usingresonance frequency analysis: Biological and biomechanicalaspects and clinical implications. Periodontol. 2000 2008; 47:51-66. 
17. Visser A, Raghoebar GM, Meijer HJ, Batenburg RH, Vissink A. Mandibular overdentures supported by two or four endosseous implants. A 5-year prospective study. Clin Oral Implants Res. 2005;16(1):19-25.

18. Shetty S, Zargar NM, Shenoy K, Rekha V. Occlusal Plane Location in Edentulous Patients: A Review. The Journal of the Indian Prosthodontic Society. 2013;13(3):142-148.

19. Giro G, Chambrone L, Goldstein A, Rodrigues JA, Zenóbio E, Feres M, Figueiredo LC, Cassoni A, Shibli JA. Impact of osteoporosis in dental implants: A systematic review. World J Orthop. 2015 18;6(2):311-5

20. Gallagher JC, Tella SH. Prevention and treatment of postmenopausal osteoporosis. J Steroid BiochemMol Biol. 2014; 142:155-170.

21. Naujokat H, Kunzendorf B, Wiltfang J. Dental implants and diabetes mellitus - a systematic review. Int J Implant Dent. 2016 Dec; 2(1): 5.

22. Shugaa-Addin B, Al-Shamiri H-M, Al-Maweri S, Tarakji B. The effect of radiotherapy on survival of dental implants in head and neck cancer patients. J ClinExp Dent. 2016; 8(2): e194-e200.

23. Gheorghiu I, Stoian I. Implant surgery in healthy compromised patients-review of literature. J Med Life. 2014; 7(2): $7-10$.

24. Donos N, Calciolari E. Dental implants in patients affected by systemic diseases. Br Dent J. 2014;217(8):425-430.

25. Helal E, El-Zawahry M, Gouda A, Elkhadem AH, Ibrahim SI. Bone Height Changes of the Mandibular Edentulous Ridge in Screw Retained Versus Telescopic Restorations for Completely Edentulous Patients. Open Access Maced J Med Sci. 2017; 5(1): 72-78.

26. Cavalcanti R, Oreglia F, Manfredonia MF, Gianserra R, Esposito M. The influence of smoking on the survival of dental implants: a 5-year pragmatic multicentre retrospective cohort study of 1727 patients. Eur J Oral Implantol. 2011;4(1):39-45

27. Kasat V, Ladda R. Smoking and dental implants. J IntSocPrev Community Dent. 2012; 2(2): 38-41.

28. Reddy SV, Kumar MP, Sravanthi D, Mohsin AHB, Anuhya V. Bruxism: A Literature Review. J Int Oral Health. 2014; 6(6): 105-109.

29. Ahuja S, Wicks R, Selecman A. Fabrication of new restorations with a consideration of oral hygiene. J Indian Prosthodont Soc. 2016; 16(3): 307-310.
30. Prasad D K, Prasad D A, Buch M. Selection of attachment systems in fabricating an implant supported overdenture. $\mathrm{J}$ Dent Implant 2014; 4:176-81.

31. Nagarajan A, Perumalsamy R, Thyagarajan R, Namasivayam A. Diagnostic Imaging for Dental Implant Therapy. J Clin Imaging Sci. 2014; 4(Suppl 2): 4.

32. Wood MR \&Vermilyea SG: A review of selected dental literature on evidence-based treatment planning for dental implants: report of the Committee on Research in Fixed Prosthodontics of the Academy of fixed Prosthodontics. J Prosthet Dent. 2004; 92:447-462.

33. Lambrecht JT, Hodel Y. Long-term results of immediately loaded inter-foraminal implants. Quintessence Int 2007; 38: 111-119.

34. Guerrero JS. Use of prophylactic antibiotic therapy in oral surgical procedures: a critical review. J Calif Dent Assoc. 2008;36(12):943-50.

35. Ahmad N, Saad N. Effects of Antibiotics on Dental Implants. J Clin Med Res. 2012; 4(1): 1-6.

36. Surapaneni H, Yalamanchili PS, Basha MH, Potluri S, Elisetti N, Kiran Kumar MV. Antibiotics in dental implants: A review of literature. J Pharm Bioallied Sci. 2016; 8(Suppl 1): S28-S31.

37. Pandey RK, Panda SS. Drilling of bone: A comprehensive review. J ClinOrthop Trauma. 2013; 4(1): 15-30.

38. Lan TH, Pan CY, Lee HE, Huang HL, Wang CH. Bone stress analysis of various angulations of mesiodistal implants with splinted crowns in the posterior mandible: a three-dimensional finite element study. Int J Oral Maxillofac Implants. 2010;25(4):763-70.

39. Pellizzer EP, Falcón-Antenucci RM, de Carvalho PS, Sánchez DM, Rinaldi GA, de Aguirre CC, Goiato MC. Influence of implant angulation with different crowns on stress distribution. J Craniofac Surg. 2011;22(2):434-7.

40. Ortegón SM, Thompson GA, Agar JR, Taylor TD, Perdikis D. Retention forces of spherical attachments as a function of implant and matrix angulation in mandibular overdentures: an in vitro study. J Prosthet Dent. 2009;101(4):231-8

41. Assad, A.S.; Hassan, S.A.; Shawky, Y.M.; and Badawy, M.M: Clinical and radiographic evaluation of implantretained mandibular overdentures with immediate loading. Impl dent, 16: 212, 2007.

42. Turkyilmaz, I. and Tumer, C.: Early versus late loading unsplintedTi Unit surface implants supporting mandibular overdentures: a 2 year report from a prospective study. J Oral Rehabil. 34: 773, 2007. 
43. Turkyilmaz, I.; Tozum, T.F.; Tumer, C. and Ozbek, E.N.: A 2-year clinical report of patients treated with two loading protocol for mandibular overdentures: early versus conventional loading. J Periodontol. 77:1998, 2006.

44. De Smet, E.; Duyck, J.; Vander Sloten, J.; Jacobs, R.; and Naert, L.: Timing of loading-immediate, early, or delayedin the outcome of implants in the edentulous mandible: A prospective clinical trial. Int J Oral MaxillofacImpl. 22: 580, 2007.

45. Nissan J, Oz-Ari B, Gross O, Ghelfan O, Chaushu G. Longterm prosthetic aftercare of direct vs. indirect attachment incorporation techniques to mandibular implant-supported overdenture. Clin Oral Implants Res. 2011;22(6):627-630

46. Vercruyssen M, Marcelis K, Coucke W, et al.: long term retrospective evaluation of the two implant supported overdenture in the mandible. Part 1: survival rate.Clin Oral Implant Res.2010;21:357-65.

47. Ueda T, Kremer U, Katsoulis J, et al.: Long term results of mandibular implants supporting an overdenture: implant survival, failure, and crestal bone level changes. Int J Oral Maxillofac Implants.2011;26:365-72.

48. Buser D, Wittneben J, Bornstein MM, Grütter L, Chappuis V, Belser UC. Stability of contour augmentation and esthetic outcomes of implant-supported single crowns in the esthetic zone: 3-year results of a prospective study with early implant placement postextraction. J Periodontol. 2011;82(3):342-349.

49. Smith DC \&Zarb GA. Criteria for success for osseointegratedendosseous implants. J Prosthet Dent. 62: 567-572, 1989

50. Albrektsson T, Zarb G, Worthington P, Eriksson AR. The long-term efficacy of currently used dental implants: a review and proposed criteria of success. Int J Oral Maxillofac Implants. 1986;1(1):11-25.

51. King, G. N.; Hermann, J. S.; Schoolfield, J. D. et al.: influence of the size of the microgap on crestal bone levels in non submerged dental implants. J Periodontol, 73: 1111, 2002.

52. Hansson, S. A.: Conical implant abutment interface at the level of the marginal bone improves the distribution of stresses in the supporting bone. An axi-symmetric finite element analysis. Clin Oral Impl Res, 14: 286, 2003.

53. Cox J. and Zarb G.: The longitudinal clinical efficiency of osseointegrated dental implants: A 3-year report. Int J Oral MaxillofacImpl, 2: 91, 1987.

54. Cochran DL, Nummikoski PV, Schoolfield JD, Jones AA, Oates TW. A prospective multicenter 5-year radiographic evaluation of crestal bone levels over time in 596 dental implants placed in 192 patients. J Periodontol. 2009;80(5):725-33.
55. Lee DW, Choi YS, Park KH, Kim CS, Moon IS. Effect of microthread on the maintenance of marginal bone level: a 3-year prospective study. Clin Oral Implants Res. 2007;18(4):465-70.

56. Hartman GA, Cochran DL. Initial implant position determines the magnitude of crestal bone remodeling. J Periodontol. 2004;75(4):572-7.

57. Griffin TJ, Cheung WS. The use of short, wide implants in posterior areas with reduced bone height: a retrospective investigation. J Prosthet Dent. 2004;92(2):139-44.

58. Neldam CA, Pinholt EM. State of the art of short dental implants: a systematic review of the literature. Clin Implant Dent Relat Res. 2012 Aug;14(4):622-32.

59. Misch CE: Implant design considerations for the posterior regions of the mouth.Implant Dent. 8: 376-386, 1999.

60. Gotfredsen K \& Holm B: Implant-supported mandibular over-dentures retained with ball or bar attachments: A randomized prospective 5-year study. Int J Prosthodont. 2000;13:125-130

61. Batenburg RH, Meijer HJ, Raghoebar GM, Van Oort RP \& Boering G: Mandibular overdentures supported by two Brånemark, IMZ or ITI implants. A prospective comparative preliminarystudy: One-year results. Clin Oral Implants Res. 1998; 9:374-383.

62. Flanagan D. Fixed partial dentures and crowns supported by very small diameter dental implants in compromised sites. Implant Dent. 2008;17:182-191.

63. Misch CE, Bidez MW. A scientific rationale for dental implant design. In: Misch CE, ed. Contemporary Implant Dentistry.2nd ed. St Louis, Mo:Mosby; 1999:329-343.

64. De Souza RF, Ribeiro AB, Vecchia MP, Costa L, Cunha TR, Reis AC, et al. Mini vs. Standard implants for mandibular overdentures: A randomized trial. J Dent Res 2015;94:1376-84.

65. Beyari MM. Comparative study between two types of implants supporting mandibular overdenture. Int J Surg Res 2015;4(2):15-18.

66. Laverty DP, Green D, Marrison D, Addy L, Thomas MB. Implant retention systems for implant-retained overdentures. Br Dent J. 2017;222(5):347-359.

67. Jofre J, et al .Effect of splinting mini-implants on marginal bone loss: a biomechanical model and clinical randomized study with mandibular overdentures. Randomized controlled trial. Int J Oral Maxillofac Implants. 2010;25(6):1137-44. 